\title{
Toward the Drosophila connectome: structural analysis of the brain network
}

\author{
Chi-Tin Shih $^{1 *}$, Olaf Sporns², Ann-Shyn Chiang ${ }^{3}$ \\ From Twenty Second Annual Computational Neuroscience Meeting: CNS*2013 \\ Paris, France. 13-18 July 2013
}

The brain can be conceptualized as a complex network. It is believed that the topological structure of the brain network is closely related to the functions of the brain [1]. Therefore, understanding the network structure of the brain is a crucial task in neuroscience. In this report, we propose a first draft of the network architecture of the Drosophila connectome at the mesoscopic scale. The structural network of the Drosophila brain is constructed from a dataset of more than 20,000 single neurons in female brain assembled in the FlyCircuit database (http:// www.flycircuit.tw) [2], the most comprehensive database of single-neuron images of the Drosophila brain to date. The nodes of the network represent mesoscopic brain regions called Local Processing Units (LPUs). The weight of the edges connecting each node pair corresponds to the number of neurons innervating the two LPUs reciprocally. The network shows hierarchical structure, pronounced small-world characteristics with high clustering and high global efficiency, and it is composed of six modules corresponding to known functional domains including the sensory modalities (including olfactory, mechano-auditory, and visual), together with the premotor and motor centers. Based on the modular structure of the network, we propose two models for the flow of information associated with intuitive and reasoning behaviors, respectively.

\section{Acknowledgements}

This work was supported in part by the National Science Council, Taiwan (NSC-100-2112-M-029-001-MY3) to CTS, Academic Summit Program of National Science Council (NSC 100-2745-B-007-001-ASP) and Brain Research Center of Aiming for the Top University Program of the National Tsing Hua University and the Ministry of Education, Taiwan to ASC.

\section{Author details}

'Department of Physics, Tunghai University, 40704 Taichung, Taiwan. ${ }^{2}$ Department of Psychological and Brain Sciences, Indiana University, Bloomington, IN 47405, USA. ${ }^{3}$ Brain Research Center, National Tsing Hua University, 30013 Hsinchu, Taiwan.

Published: 8 July 2013

\section{References}

1. Bullmore E, Sporns O: Complex brain networks: graph theoretical analysis of structural and functional systems. Nature Reviews Neuroscience 2009, 10:186-198.

2. Chiang AS, et al: Three-dimensional reconstruction of brain-wide wiring networks in Drosophila at single-cell resolution. Current Biology 2011, 21:1-11.

doi:10.1186/1471-2202-14-S1-P63

Cite this article as: Shih et al:: Toward the Drosophila connectome: structural analysis of the brain network. BMC Neuroscience 2013 14(Suppl 1):P63.

* Correspondence: shih.chi.tin@gmail.com

'Department of Physics, Tunghai University, 40704 Taichung, Taiwan

Full list of author information is available at the end of the article

Submit your next manuscript to BioMed Central and take full advantage of:

- Convenient online submission

- Thorough peer review

- No space constraints or color figure charges

- Immediate publication on acceptance

- Inclusion in PubMed, CAS, Scopus and Google Scholar

- Research which is freely available for redistribution

Submit your manuscript at www.biomedcentral.com/submit
C Biomed Central 